\title{
Four Idioms, One Home
}

\section{ANDREW COLOPY}

Rice University

House or Apartment? Neither. Enter the Accessory Dwelling. Affordable housing for the sharing economy. Domesticity for today's non-nuclear family.

The turn to legitimacy for this once informal housing type is sensible. Accessory dwellings offer real potential to lower costs, increase density and diversify housing options within an otherwise intractable suburban expanse.

Yet, as a subjugated type-second always to a primary dwelling-they pose a challenge to the conditions of privacy, security, and comfort that "home" has come to represent. Indeed, if not imagined anew, the conventional secondary dwelling may serve to index and deepen the disparity of our era.

What's needed is a diverse set. Difference in size, position, and presence. Not each individually-an impossibilitybut en masse. The conventions of being second-smaller, backgrounded, isolated-are the inequalities that establish inequity. Diversity is created neither by total opposition nor incremental addition: either-or, both-and... not enough. The part-to-part is insufficient. The whole must set the terms. Community through the uncommon.

Here are a set of four idioms. They reside in front, side, and back. Necessarily small, then sometimes expansive or at least seemingly so. If isolated, then communal. We invite you to follow "A," who meanders through a day at home. 


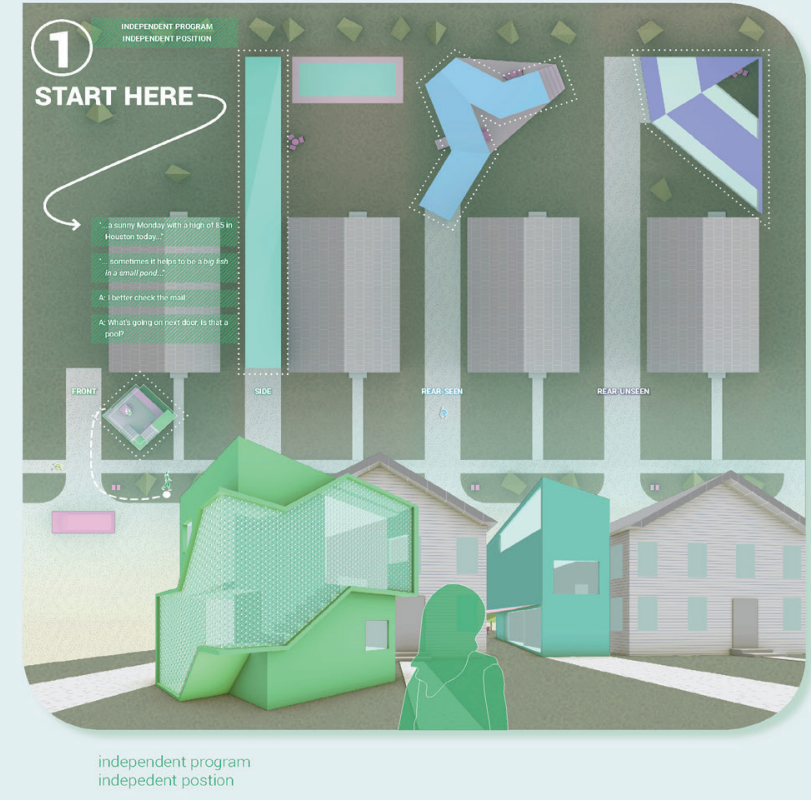

\section{four idioms one home}
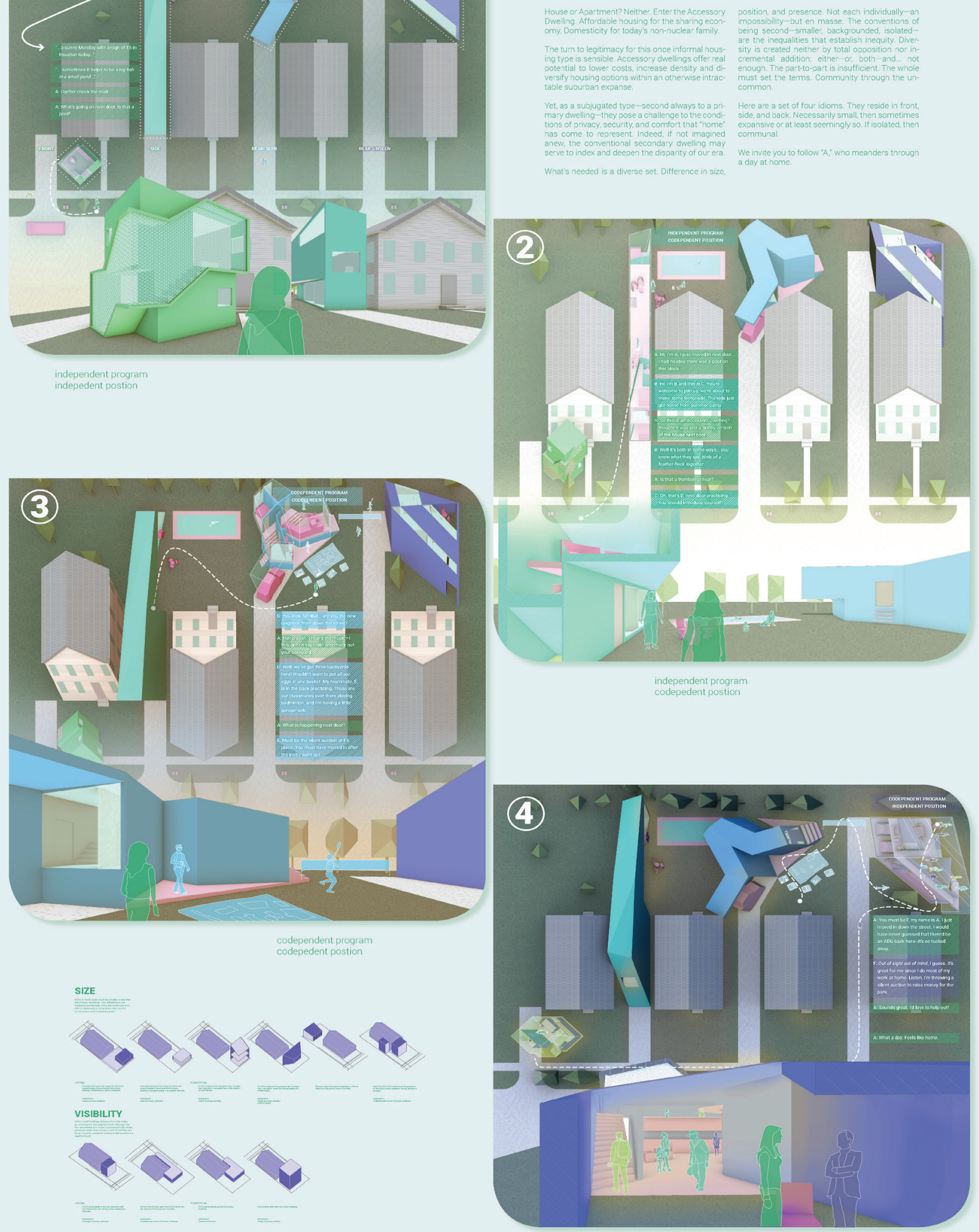